\title{
Addressing Internal Displacement through National Laws and Policies: A Plea for a Promising Means of Protection
}

\section{NINA SCHREPFER*}

\begin{abstract}
Unlike in the case of refugees, there is neither an international convention nor a dedicated UN agency in place to protect internally displaced persons. This discrepancy has, however, not stopped the law on internal displacement from emerging, filling the normative void around internal displacement. The UN Guiding Principles on Internal Displacement of 1998, a soft law instrument on the protection of the rights of internally displaced persons, is a success story, having faced disapproval in the past but now being an internationally recognized standard. Most importantly, the principles have become the point of reference for states developing national laws and policies addressing internal displacement. These national developments across the globe are an expression of the recognized and assumed responsibility of national authorities for the displaced and, although such instruments show shortcomings and weaknesses, their greater good for the better protection of internally displaced persons is undeniable. While national instruments on the protection of internally displaced persons are a still emerging tool of protection, they are also the future of the UN Guiding Principles on Internal Displacement.
\end{abstract}

\section{Introduction: a protection discrepancy}

International attention to the plight of the over 27 million internally displaced persons (IDPs) displaced by armed conflict, ${ }^{1}$ and the millions more displaced by natural disasters, ${ }^{2}$ has increased. However, a coherent

\footnotetext{
* MLaw (International and European Law). Legal Advisor to the former Representative of the UN Secretary-General on the Human Rights of Internally Displaced Persons at UNHCR until November 2010. In this capacity, supported, in 2010 and 2011, the Governments of Kenya and Yemen in the process of developing their national instruments on internal displacement. Currently working as Legal Advisor in Human Rights and Humanitarian Affairs at the Law Faculty of the University of Bern, Switzerland.

${ }^{1}$ Internal Displacement Monitoring Centre/Norwegian Refugee Council, 'Global Overview of Trends and Developments in 2010' (Mar 2011), 13-18.

${ }^{2}$ Internal Displacement Monitoring Centre, 'Displacement due to natural hazard-induced disasters, Global estimates for 2009 and 2010' (2011), 4. This report offers a reliable figure of 36.1 million IDPs displaced by sudden onset disasters in the course of 2008, 16.7 million IDPs in 2009, and 42.3 million in 2010 .
} 
response to address their rights and needs, and to resolve internal displacement situations, remains a humanitarian and human rights challenge. ${ }^{3}$ The protection discrepancy between refugees and IDPs has been deplored, in particular, the absence of a normative framework comparable to the 1951 Convention relating to the Status of Refugees, ${ }^{4}$ and the pitfalls in the institutional arrangements catering for the displaced within states in the absence of an organization comparable to the dedicated UN Agency for Refugees (UNHCR). When the issue was eventually addressed by the international community after the fall of the iron curtain, those who had hoped for a similar convention and a dedicated institution for IDPs were disappointed. Refugees cross a state border to access substitute international protection in the absence of protection from their own state, but IDPs who do not or are unable to leave their home country remain largely unprotected while closer to the source of danger. ${ }^{5}$ Thus, crossing borders matters and, at first sight, indicates a serious gap in the protection of the rights of IDPs at the normative, the institutional and the operational level. This article looks at the normative developments to better protect displaced people.

The answer to this protection gap at the normative level was not the inclusion of IDPs under the 1951 Convention relating to the Status of Refugees. Covering conflict-induced IDPs within the scope of the 1951 Convention would have been, at best, inappropriate, and could have created new problems for the protection of IDPs. The fact that they have not crossed a border raises the issue of national sovereignty and the sovereign equality of states. ${ }^{6}$ Unlike refugees, IDPs remain within the territory of their own state and are therefore protected under domestic law, as all state citizens, requiring neither a right to admission and stay, nor a particular status with attributed rights. Inclusion in the Refugee Convention was therefore never considered as a solution to the protection gap, nor was a new legally binding instrument for IDPs. A comprehensive study of 1995, commissioned by Francis Deng, thoroughly analyzing the rules of international law applicable to internal displacement concluded that existing law sufficiently protects the rights of IDPs in many aspects. It did, however, identify gaps and legal imprecision in the existing protection framework applicable to IDPs. ${ }^{7}$ The need for a new convention was thus not proved and no new instrument has been put forward. Due to the limits and

\footnotetext{
${ }^{3}$ According to the UN Secretary-General Ban Ki-Moon, internal displacement is 'arguably the most significant humanitarian challenge that we face'; see Internal Displacement Monitoring Centre/ Norwegian Refugee Council, 'Global Overview of Trends and Developments in 2007' (Apr 2008), 8.

${ }^{4}$ Convention relating to the Status of Refugees, 198 UNTS 150, entered into force 22 Apr 1954.

${ }^{5}$ R Cohen, FM Deng, Masses in Flight: The Global Crisis of Internal Displacement (1998), 126, citing the former UN Secretary-General Boutros Boutros-Ghali.

${ }^{6}$ Art 2(1) UN Charter.

${ }^{7}$ Report of the Representative of the Secretary-General, 'Internally Displaced Persons: Compilation and Analysis of Legal Norms Part I and II', UN doc E/CN.4/1996/52/Add. 1 \& 2, 5 Dec 1995, and 11 Feb 1998.
} 
weaknesses of international treaty-making in general, ${ }^{8}$ and the difficulties in the realm of human rights law more specifically, a different option was suggested to fill the normative protection gap in the protection of IDPs, ${ }^{9}$ bypassing such difficulties in international legislation and, at the same time, taking into account the strong assertions of national sovereignty by states.

\section{The success story of the Guiding Principles on Internal Displacement}

The answer to the normative void in the protection of IDPs was the Guiding Principles on Internal Displacement ${ }^{10}$ (Guiding Principles) that were introduced to the former UN Commission on Human Rights by the first Representative of the UN Secretary-General on IDPs, Francis Deng. The Guiding Principles were the result of an unconventional and innovative method ${ }^{11}$ developed by a group of legal experts directed by Prof Walter Kälin under the auspices of the Representative of the UN Secretary General. They set forth the protection of IDPs, covering displacement, protection and assistance in a displacement situation, and also the issue of a durable solution. ${ }^{12}$ Most notably, the Guiding Principles contain a - now internationally accepted - definition of an IDP, replacing previous definition attempts, ${ }^{13}$ that includes major causes of displacement and removes the temporal and numeric limitations of earlier definitions.

The Guiding Principles are a so-called soft law instrument providing a set of applicable guidelines that are firmly grounded in hard law, that

${ }^{8}$ S Bagshaw, Developing a Normative Framework for the Protection of Internally Displaced Persons (Ardsley, 2005), 11-12 \& 19-69. In particular, the time-consuming nature of international legislation while facing an imminent displacement challenge, and other problems entailed in international treaty making, especially, the risk of non-ratification of such an international instrument by relevant states, as well as considerations of national sovereignty watering down existing international human rights standards for IDPs, were considered to be critical impediments to a successful legislative exercise.

${ }^{9}$ On these risks, see W Kälin, 'How Hard is Soft Law? The Guiding Principles on Internal Displacement and the Need for a Normative Framework', in Brookings-CUNY Project on Internal Displacement (ed), Recent Commentaries about the Nature and Application of the Guiding Principles on Internal Displacement (April 2002), 3-7. See also, W Kälin, 'The Guiding Principles on Internal Displacement as International Minimum Standard and Protection Tool' (2005) 24 RSQ 29; and, R Cohen, 'Strengthening Protection of IDPs: The UN's role' (2006) Georgetown Journal of International Affairs 102-3.

${ }^{10} \mathrm{UN}$ doc E/CN.4//1998/53/Add.2, 11 Feb 1998.

${ }^{11}$ More specifically, on the development of the Guiding Principles on Internal Displacement, see Bagshaw, above n 8, 71-139; R Cohen, 'The Guiding Principles on Internal Displacement: An Innovation in International Standard Setting' (2004) 10 Global Governance.

${ }^{12}$ For a short elaboration on the content of the Guiding Principles, see ED Mooney, 'Principles of Protection for Internally Displaced Persons' (2000) 38 International Migration.

${ }^{13}$ In 1989, at the International Conference on the Plight of Refugees, Returnees and Displaced Persons in Southern Africa, the then UN Secretary-General defined IDPs in his report as, 'persons who have been forced to abandon their homes or their normal economic activities, while remaining inside their countries of origin, because their lives, security or freedom have been threatened by generalized violence, armed conflicts, internal upheavals, or similar events seriously disturbing the public order', UN doc A/44/520, 28 Sept 1989, para 72. In a subsequent report in 1992, the Secretary-General used 
is, rules of human rights and international humanitarian law, ${ }^{14}$ and, as such, are neither a discretionary instrument nor legally binding, ${ }^{15}$ but an authoritative restatement of applicable rules of public international law. On their introduction fourteen years ago they were initially received with suspicion by some Governments, as they did not result from traditional inter-state negotiations and were never formally adopted by a legitimate inter-governmental body. ${ }^{16}$ Francis Deng and, in particular, the recent Representative of the UN Secretary-General, Walter Kälin, strongly promoted the Guiding Principles at the international, regional and national levels, and were catalysts for their recognition and further development.

In 2005, the UN Secretary-General in his report, 'In Larger Freedom', urged UN member states to accept the instrument as 'the basic international norm for protection' of IDPs. ${ }^{17}$ The Guiding Principles' international recognition as 'an important international framework for the protection of internally displaced persons' 18 by the World Summit of States was an international breakthrough that was subsequently reaffirmed by the General Assembly recognizing that 'the protection of internally displaced persons has been strengthened by identifying, reaffirming and consolidating specific standards for their protection, in particular through the Guiding Principles on Internal Displacement'. ${ }^{19}$

At the regional level, Africa was the clear trailblazer with the Great Lakes Protocol on the Protection and Assistance to Internally Displaced Persons of 2006 (Great Lakes Protocol) and, in 2009, Kampala adopted the African Union Convention for the Protection and Assistance of Internally Displaced Persons in Africa (Kampala Convention). The Great Lakes Protocol's objectives are to establish a regional framework to ensure the adoption and

the term IDPs to describe those 'who have been forced to flee their homes suddenly or unexpectedly in large numbers; as a result of armed conflict, internal strife, systematic violations of human rights or natural or man-made disasters; and who are within the territory of their own country', 'Analytical report of the Secretary-General on internally displaced persons', UN doc E/CN.4/1992/23, 14 Feb 1992, para 17. Also, the IDP definition contained in art 1 of the London Declaration of International Law Principles on Internally Displaced Persons, as adopted by the International Law Association in 2000, did not have a breakthrough.

${ }^{14}$ The Guiding Principles clarify some grey areas and address gaps in the applicable law and go beyond human rights and international humanitarian law. These areas for clarification and gaps had been identified in the Compilation and Analysis of Legal Norms (Part I), above n 7, 201-4. The Annotations to the Guiding Principles spell out the legal foundation of each principle in more detail; see W Kälin, 'Guiding Principles on Internal Displacement: Annotations', Studies in Transnational Legal Policy, No 38 (revised edition, 2008).

${ }^{15}$ See Kälin, How Hard is Soft Law?, above n 9, 7-9.

${ }^{16}$ Egypt and Sudan argued against the Guiding Principles with reference to the absence of the traditional inter-state negotiation that should have preceded them. See also, FM Deng, 'The Global Challenge of Internal Displacement' (2001) 5 Journal of Law \& Policy 149.

${ }^{17}$ Report of the UN Secretary-General, 'In Larger Freedom: Towards Development, Security and Human Rights for All', UN doc A/59//2005, 21 Mar 2005, para 210.

${ }^{18}$ World Summit Outcome Document, UN doc A/60/L.1, 15 Sept 2005, para 132.

${ }^{19}$ UNGA res, 64/162, 2009, preambular para 10. 
implementation of the Guiding Principles in the region and to provide a legal basis for domesticating the Guiding Principles into national legislation. ${ }^{20}$ The Kampala Convention recognizes the Guiding Principles in the preamble and sets forth provisions in the spirit of the Guiding Principles and even goes beyond them. The Parliamentary Assembly of the Council of Europe recognized the Guiding Principles in 2003 as a 'standard for governments and other responsible authorities and intergovernmental and non-governmental organizations' and urged them to promote, disseminate, observe and incorporate them into domestic laws. ${ }^{21}$ The Council's Committee of Ministers subsequently attributed international recognition and authority to the Guiding Principles and further stressed its commitment to the spirit and letter of the principles and recommended their domestic adoption and implementation by European member states. ${ }^{22}$ The Organization of American States in recalling the Guiding Principles recognized their use by a number of countries in the region and urged member states to continue to use them and consider their domestic implementation. ${ }^{23}$

Finally, at the national level, a growing number of countries around the world have enacted national laws, policies, strategies or other instruments on internal displacement, or are in the course of doing so. Some of these instruments predate the Guiding Principles ${ }^{24}$ but the large majority and in particular the newer national instruments have used the Guiding Principles as their basis and fully or partially reflect them. Their use as a point of reference for developing national instruments on the protection of IDPs has consistently been the intention of the Representative of the SecretaryGeneral. ${ }^{25}$ In 2008, Kälin issued a Manual for Law and Policymakers ${ }^{26}$ to reinforce and further support this trend at the national level.

The Guiding Principles have come a long way, from the initial disapproval to an international and regional recognition as an instrument for the protection of IDPs worldwide and a key point of reference for

\footnotetext{
${ }^{20}$ Art 2(1) and (3), and art 6, Great Lakes Protocol.

${ }^{21}$ Council of Europe, Parliamentary Assembly Recommendation 1631 (2003) 'Internal displacement in Europe', paras 11-12 and 14-15.

${ }^{22}$ Council of Europe, Committee of Ministers Recommendation 6 (2006) 'Internally Displaced Persons'. This call for domestic incorporation was repeated in the Parliamentary Assembly's Recommendation 1862 (2009) 'Environmentally induced migration and displacement: a $21^{\text {st }}$ century challenge', para 6.4 .

${ }^{23}$ Organization of American States, General Assembly Resolution AG/RES 2417 (XXXVIII-O/08), 2008, Internally Displaced Persons, preamble and operative paras 1-3; General Assembly Resolution AG/RES 2508 (XXXIX-O/09), 2009, Internally Displaced Persons, preamble and operative paras $1-2$.

${ }^{24}$ National instruments in Azerbaijan, Colombia and Georgia pre-date the Guiding Principles. However, in Colombia and Georgia, processes to complement or revise existing legislation have taken into account the guidance provided by the Guiding Principles.

${ }^{25}$ Report of the Representative of the Secretary-General on Internally Displaced Persons, UN doc E/CN.4/1998/53, 1998, para 24.

${ }^{26}$ Brookings Institution - University of Bern Project on Internal Displacement, 'Protecting Internally Displaced Persons: A Manual for Law and Policymakers’ (2008) (IDP Manual).
} 
national instruments on internal displacement. The availability of the Guiding Principles in almost fifty languages has certainly contributed to their worldwide dissemination and recognition. There is even a noticeable tendency to recognize the Guiding Principles as customary international law. ${ }^{27}$ This process is still in its nascence, but is, nevertheless, a trend worth noting.

It is particularly encouraging that an increasing number of states are adopting national instruments on internal displacement. These national instruments are likely to become the future of the Guiding Principles and the driving force in the further development of the law on internal displacement. ${ }^{28}$ The task of national law and policy making ${ }^{29}$ is part of any government's primary responsibility to protect IDPs.

\section{National responsibility for IDPs - a concept with limits}

Primary national responsibility for IDPs is one of the key principles embodied in the Guiding Principles and is founded in the concept of sovereignty as responsibility. IDPs as citizens or habitual residents of their country should receive assistance and protection primarily from their government. ${ }^{30}$ Protecting one's own people in distress is an expression of a state's sovereignty and constitutes a core difference to the situation of refugees who receive substitute international protection in the absence of protection from their home country.

\subsection{National instruments on internal displacement - a sovereign task}

National responsibility is a demanding concept: national authorities have to engage in a comprehensive response that is tailored to the particular circumstances of the displacement situation in their country and that is flexible enough to adapt to the changing needs of the population in the

\footnotetext{
${ }^{27}$ The Iraqi National Policy on Displacement of July 2008, para 5(3), declares that the Guiding Principles have become 'part of international law'. Similarly, the Government of Germany stated that the Guiding Principles 'can by now be considered to be international customary law'; see, 'Achter Bericht der Bundesregierung über ihre Menschenrechtspolitik in den auswärtigen Beziehungen und in anderen Politikbereichen', 150.

${ }^{28}$ W Kälin, 'The future of the Guiding Principles' (2008) 39 Forced Migration Review (Special Issue on Ten Years of the Guiding Principles on Internal Displacement). Incorporation into national legislation was also the first recommendation by the Oslo Conference on the occasion of the Principles' tenth anniversary, ibid, 7.

${ }^{29}$ The term 'national law and policy making' is a non-technical term to describe processes through which national instruments on internal displacement, laws, policies, strategies, and plans, are developed.

${ }^{30}$ Principle 3(1) of the Guiding Principles states: 'National authorities have the primary duty and responsibility to provide protection and humanitarian assistance to internally displaced persons within their jurisdiction'. This principle is echoed in principle 25(1) with regard to humanitarian assistance, and in principle 28(1) relating to durable solutions.
} 
different stages of the displacement process. ${ }^{31}$ Devising national instruments on internal displacement forms part of a government's national responsibility to protect IDPs and is an inherently sovereign task. The development of a national instrument addressing displacement situations is also critical for a state to better and more efficiently assume its primary responsibility towards displaced populations in a suitably comprehensive and tailored manner. ${ }^{32}$ National instruments on internal displacement often make it easier for states to assume their primary responsibility for IDPs, rather than this responsibility being imposed by an international document. However, developing a national instrument to address internal displacement is often not on the top of a government's agenda, or on that of international actors, because the primary focus during a humanitarian crisis involving internal displacement is generally the operational response, namely, the provision of shelter, food, potable water, healthcare, education, sanitation facilities, and the like, in order to ensure the survival of the population and to address their immediate needs. While this prioritization is appropriate in the immediate emergency phase, the longer the displacement lasts, the initial life-saving response can become an ad hoc and unsystematic process, neglecting many of the rights and needs of the displaced. Neglecting to protect some of the rights of the displaced has, in its most extreme form, resulted in the tragic phenomenon of the 'well-fed dead', a notion seen during the bloodshed on the territory of the former Yugoslavia, illustrating the importance of also protecting the economic, social and cultural rights, alongside the civil and political rights, of the displaced. Given that many of today's displacement situations are protracted, lasting five, ten, or even twenty years, it is even more important to consolidate a planned and systematic approach to find durable and lasting solutions for the displaced people. A national instrument helps authorities, but also international actors, to be prepared and to better tailor the response to ensure an adequate and holistic response to displacement, which in most instances is not short-term, lasting well beyond the emergency period. Such a national instrument could, as a preparedness measure, be part of effective contingency planning to allow for a smooth transition from the immediate emergency phase to the longer-term response, which has to take into account the changing needs of the displaced people.

\footnotetext{
${ }^{31}$ National authorities, including all relevant branches and levels of government, have to be prepared for and engage in a comprehensive national response to internal displacement encompassing all IDPs, as well as vulnerable and minority groups, due to all causes, be it conflict, generalized violence or disaster, and address all needs of the displaced population in all affected areas, including areas which may not easily be accessible or under control of insurgent or tribal groups. See, the Brookings Institution-University of Bern Project on Internal Displacement, 'Addressing Internal Displacement: A Framework for National Responsibility' (Apr 2005), 9-11.

${ }^{32}$ National law and policy making is thus also recognized as two key benchmarks for assuming national responsibility in the Framework for National Responsibility, ibid, 16-17.
} 
While the responsibility towards IDPs puts a high burden on national authorities, no state will repudiate its responsibility because it is grounded in its sovereignty. This is where the actual strength of the concept of national responsibility lies. The development of national laws, policies or strategies is more strongly linked to the sovereignty of states, than other more operational tasks.

\subsection{Two factors affecting national responsibility: lacking capacity and unwillingness}

The fact that a state cannot reject its primary responsibility towards its IDPs does not mean that it is willing and capable of assuming it.

It is not unusual for a war-stricken or disaster-affected country to have only limited capacity and means available to assist and protect its displaced population due to other challenges it may face in the context or wake of conflict or disaster. What is important, and can realistically be expected, is for states to have the fate of displaced people as a priority on the radar screen: politically, financially and operationally. The longer the displacement lasts, the more complex it gets to find solutions to it. A protracted displacement situation does not only put enormous strain on the displaced themselves, but also on host communities and the country itself. Neglect of IDPs may also trigger unrest among displaced communities and become a security threat, as demands for protection of their rights become more desperate. A national instrument on internal displacement may assist national authorities to respond more efficiently with limited capacities and to manage the rational allocation of the resources available to avoid the risk of protracted displacement and civil unrest to the extent possible.

The concept of national responsibility for IDPs can be misused or intentionally not applied. While many states do insist on their primary role, this is not always driven by the genuine intention to assume this role towards the displaced, but rather to restrict humanitarian access and the intervention of international actors. ${ }^{33}$ In other situations the state may have no interest in or intention of protecting IDPs, where it has induced, or at least contributed to, the displacement through its actions, or in cases where the majority of the displaced population is perceived by the government to be affiliated to or to support the opposing party. As shown in Yemen, the process of developing a national instrument on internal displacement can help to find a more positive approach to the primary national responsibility of national authorities, and the confirmation of this responsibility to assist and protect all IDPs in a non-discriminatory manner in a national instrument may assist in preempting such negative outcomes.

The concept of national responsibility has limitations in failing state situations where assuming this responsibility is not possible. An example is

\footnotetext{
${ }^{33}$ Such practice is particularly seen from strong states such as Sri Lanka, Pakistan or Myanmar.
} 
Somalia, where the Transitional Federal Government, without the necessary financial means, and with Ministers often absent from the country and under permanent threat, cannot possibly assume its primary responsibility towards the 1.5 million IDPs. Similar problems exist, though to a less extreme extent, in countries like Afghanistan, the Central African Republic and Yemen, amongst others. It is, however, interesting to see that countries, like Yemen and the Central African Republic, are in the course of developing national instruments addressing internal displacement despite their institutional fragility. Although implementation of these instruments will, in such circumstances, be very difficult.

These problems and limitations notwithstanding, national responsibility for IDPs is a given component of state sovereignty and firmly grounded in the sovereign equality of all states. ${ }^{34}$ While the concept of sovereignty as responsibility has its shortcomings, the potential of the non-rejectable responsibility of states towards IDPs, including national law and policy making, is a strength that should not be overlooked.

\subsection{The important role of international actors in national law and policy making}

The concept of national responsibility for IDPs also has an external component. The state's primary responsibility to care for IDPs also entails the duty to not arbitrarily refuse offers by international actors to support and complement national efforts for IDPs, where such efforts are inadequate. ${ }^{35}$ Support from international actors is often indispensible in times of humanitarian crisis involving internal displacement.

International humanitarian and human rights actors play an important role in assisting and protecting IDPs where national capacities or willingness are lacking. Although international actors often insist that they assist governments and complement their efforts, they increasingly resort to substituting the functions of national authorities. While international actors play an important role in assisting governments in developing a national instrument, it is usually not wise for them to take over this task in substitution, because it is strongly linked to the sovereignty of a state, rather than to operational activities. Substituting such tasks can disenfranchise the national authorities and therefore requires caution. Supporting national authorities in devising a national instrument on internal displacement is, however, important, and provides an excellent capacity building opportunity. The process of developing such an instrument requires indepth appraisal of the displacement situations; the challenges, the gaps in the response, and the prospects for a viable solution. The results of

\footnotetext{
${ }^{34}$ Art 2(1) UN Charter.

${ }^{35}$ This is reflected in principle 25(2) of the Guiding Principles.
} 
this process strengthens capacities, as it clarifies basic notions, concepts and normative ideas framing and strategizing a response to internal displacement, and may even lead to a more efficient use and allocation of resources. International actors also profit from the process of developing a national instrument on internal displacement. Such a process may be used to build mutual trust and provides an opportunity for international actors to put forward ideas and priorities for such an instrument, which can then be owned by a government. The document itself may furthermore facilitate humanitarian operations by outlining the basis and parameters of the overall response to the protection of IDPs on the part of the government.

Since the humanitarian reform in 2005 and the introduction of the cluster approach, the task of supporting national authorities in their endeavours to devise national instruments on internal displacement falls to the protection clusters at the global and national levels, mostly led by UNHCR. UNHCR, as protection cluster lead, has played an instrumental role in many national processes to develop such instruments, including in Colombia, Georgia, Kenya, the Central African Republic and Yemen.

\section{National law and policy efforts: reflections of reality}

\subsection{International and regional calls for national instruments on internal displacement}

The broad recognition of the Guiding Principles has been accompanied by unequivocal calls for their national domestication. The Representative of the Secretary-General has stressed the need for developing national instruments on internal displacement early on. He has addressed the international community on this through annual reporting and has discussed it with governments directly in the course of country visits. ${ }^{36}$ As such, the Representative was a catalyst for many such national developments, including in Nepal, Uganda, Serbia, Georgia, recently in Yemen, and in ongoing efforts in the Central African Republic, as well as being a substantial contributor to many other such processes. The former UN Secretary-General, Kofi Annan, reiterated his Representative's calls to adopt the Guiding Principles through national legislation. ${ }^{37}$ In Africa, domesticating the Guiding Principles has become a legal obligation for the Great Lakes states and an emerging legal requirement under the Kampala

\footnotetext{
${ }^{36}$ See, amongst others, reports to the General Assembly, UN doc A/58/393, 26 Sept 2003, paras 20-21; to the former Commission on Human Rights, UN doc E/CN.4/2004/77, 4 Mar 2004, para 19; to the Human Rights Council, UN doc A/HRC/10/13, 9 Feb 2009, paras 6, 12, 14-16; the mission report on Nepal, UN doc E/CN.4/2006/71/Add. 2, 7 Jan 2006, para 67 (a); to the Central African Republic, UN doc A/HRC/16/43/Add.4, 18 Jan 2011, paras 44-51.

${ }^{37}$ Report of the UN Secretary-General, In Larger Freedom, above n 17, para 210.
} 
Convention ${ }^{38}$ once entered into force. ${ }^{39}$ Also Africa's sub-regional organizations $^{40}$ - ECOWAS, IGAD and SADC - have, soon after the introduction of the Guiding Principles, recommended their national incorporation. ${ }^{41}$ While not establishing legal obligations, relevant organs in other regions, such as the Council of Europe ${ }^{42}$ or the Organization of American States, ${ }^{43}$ have also repeatedly called upon their member states to develop national frameworks to better protect and assist IDPs. Regional bodies of the Asian region have not yet recommended such action to its member states and the League of Arab States has also remained tacit as yet. However, internal displacement has been addressed in a number of regional and national workshops, in particular in the Asian region, and the existence of national instruments in countries in both regions reflects the awareness of the topic and the importance of its domestic regulation.

\subsection{The value added by national instruments on internal displacement}

Internal displacement shatters the lives of individuals, may be a burden on hosting communities, and is a challenge for the country concerned and a risk for regions. Addressing internal displacement requires great effort and high institutional and financial capacities of national authorities, often complemented by support from the international community. National instruments on internal displacement put governments in a better position to address the displacement challenge in their country in a strategic, planned and concerted manner and to thus make a difference in the protection of the rights of IDPs, as illustrated by the experience in Colombia:

Before 1997, the State responded to forced displacement in an ad hoc and ineffective manner. A specific national policy to address the problem did not exist. Aid

${ }^{38}$ Art 3(2)(a) of the Kampala Convention requests state parties to 'incorporate their obligations under this Convention into domestic law by enacting or amending relevant legislation on the protection of, and assistance to, internally displaced persons in conformity with their obligations under international law'. While not relating directly to incorporating the Guiding Principles but the obligations under the convention, it should be borne in mind that the convention largely reflects the Guiding Principles.

${ }^{39}$ Art 16(1) Kampala Convention requires 15 ratifications in order to enter into force. At the time of completion of this manuscript, 11 states out of 31 signatories have ratified the instrument: Uganda, Chad, Central African Republic, Sierra Leone, Zambia, Gambia, Guinea-Bissau, Mali, Togo, Gabon, and Somalia.

${ }^{40}$ See, eg, Khartoum Declaration adopted by the Ministerial Conference on Internally Displaced Persons in the IGAD Region, 2 Sept 2003, at Conference on Internal Displacement in the IGAD Sub-Region, Report of the Experts Meeting, Khartoum, 30 Aug-2 Sept 2003, Appendix E. The Representative of the UN Secretary-General refers in his report to efforts of ECOWAS member states, UN doc E/CN.4//2003/86, 21 Jan 2003, para 32.

${ }^{41}$ See, E Mooney, 'Developing National Law, Policy and Strategies around the African Union Convention for the Protection and Assistance of Internally Displaced Persons in Africa', African Union-Civil Society Organizations Pre-Summit on Internally Displaced Persons in Africa, Kampala, Uganda, 13-15 Oct 2009, 1 .

${ }^{42}$ Parliamentary Assembly Recommendation 1631, above n 21; Committee of Ministers Recommendation 6, above n 22; Parliamentary Assembly's Recommendation 1862, above n 22.

${ }^{43}$ General Assembly Resolutions, above n 23. 
of any sort was provided to IDPs within the general social welfare and emergency response systems. Overall, the problem was given an extremely low priority and accorded little visibility within the Colombian public sphere. The adoption by Congress of Law 387 of 1997 [on internal displacement] represented a major breakthrough.... it is undeniable that the very adoption of Law 387 of 1997 represented a substantial achievement ... ${ }^{44}$

This statement by former Constitutional Judge of Colombia, Manuel José Cepeda, succinctly points out why national instruments on internal displacement matter for a country and for the protection of IDPs.

Reasons for developing national instruments on internal displacement are manifold. Irrespective of whether it is a law, policy, strategy or any other instrument, developing such national instruments is a task inherently anchored in national sovereignty and, as such, part of the primary responsibility of national authorities, as discussed above. ${ }^{45}$ By developing such an instrument, a government not only acknowledges the existence of a displacement situation within its territory, but also signals the recognition and acceptance of the national primary responsibility towards IDPs. ${ }^{46}$ Depending on a state's obligations assumed under regional and international law, the development of a national instrument on internal displacement may even be an obligation. While IDPs remain protected under the national Constitution and applicable national laws of a country, domestic legislation is often insufficient to address the particular needs and vulnerabilities of IDPs. A national instrument on internal displacement can help to avoid legal pitfalls. A coherent policy on internal displacement will render a government a reliable and credible actor for the displaced population and for the international community, including donors. National endeavours will be particularly positively perceived where they respond to regional and international obligations and meet respective standards, such as those contained in the UN Guiding Principles on Internal Displacement or respective regional instruments. A national instrument may also facilitate cooperation and coordination among the variety of governmental, non-governmental, national and international actors often involved in the response to a displacement crisis. A national instrument well-tailored to the country-specific displacement context will be an important practical

\footnotetext{
${ }^{44} \mathrm{MJ}$ Cepeda Espinosa, 'The Constitutional Protection of IDPs in Colombia' in RA Rivadeneira (ed), Fudicial Protection of Internally Displaced Persons: The Colombian Experience (Nov 2009), 6-7.

${ }^{45}$ See sub-section 3.1 above.

${ }^{46}$ S Carr, 'From Theory to Practice: National and Regional Application of the Guiding Principles' (2009) 21 IJRL 34, at 46, argues that today it is no longer a question of governments recognizing their responsibility towards the displaced. However, while this seems disputatious when looking at the difficult dialogues the Representative of the Secretary-General had, eg, with the Governments of Yemen or Pakistan, this statement also ignores the fact that states not only need to recognize national responsibility towards the displaced, but also be willing and able to assume it. This is where national instruments may provide invaluable support.
} 
framework that supports coordinated planning and a systematic and effective response. As such, this instrument has the potential to better ensure that the rights of all IDPs are protected and that no one is neglected, discriminated against or left out and, more generally, avoids a protraction of the needs of the displaced. It may also enhance the efficiency of the response, including by ensuring a more rational allocation of capacities.

\subsection{Why the process matters}

The process through which national instruments on internal displacement are developed matters. It matters in itself, as well as for the outcome document. National law and policy makers should be aware of the importance of the process to develop a national instrument and the decisions to be made in its course.

Arguably, there are two types of processes. First, the governmental (or ministerial) process, which develops a national instrument in accordance with the national legislation and procedures prescribed for the elaboration and adoption of national laws, policies, strategies or plans. Such a governmental process does not necessarily need to remain exclusive, but may be opened to consultations with relevant national or international actors. Sudan and the Philippines, for example, have held consultations based on an existing governmental draft, while retaining the decision making power of whether or not to act on recommendations received. It is also conceivable that third parties, such as consultants or a research or policy institute, could draft a national instrument, either having been commissioned by a government to do so, or initially without governmental involvement, followed by advocacy work to campaign for the adoption of the draft by the relevant authorities.

Secondly, there are consultative processes, characterized by a higher degree of consultations with relevant national, regional and international actors than in governmental processes; or joint processes, between the government, the present international community, national civil society and representatives of the displaced communities. The majority of recent or ongoing processes to develop a national instrument on internal displacement belong to this second category, most notably, the processes in Kenya and Yemen, in 2010, and the ongoing efforts in the Central African Republic, which have this inclusive character. In Kenya, the draft national policy was strongly reaffirmed at the end of a three-month consultation period by a stakeholder's forum held in Nairobi, a gathering of over 100 relevant stakeholders, including representatives from displaced communities. $^{47}$

\footnotetext{
${ }^{47}$ IRIN Humanitarian News and Analysis, 'Kenya: Draft policy offers new hope for IDPs' (19 Mar
} 2010), <http://www.irinnews.org/Report.aspx?ReportId=88485>, accessed 24 Mar 2011. 
The character of the process often depends on how it was initiated. Some instruments are initiated by international calls, such as the Peace-Building Commission in the Central African Republic, or the Representative of the UN Secretary-General in Yemen. Others are initiated by responsible actors of the government, or result from strong advocacy efforts by national civil society and/or present international actors.

The role of national governments is, however, critical in developing national instruments, regardless of the process and form of initiation, because it is a task intrinsically linked to state functions and sovereignty. Equally important is the inclusion of representatives of the displaced and displacement-affected communities in the process. This ensures that their views on their own capacities are taken into account, and brings a different perspective to the process, with other emphases and priorities that need to be addressed. Experience shows that displacement-affected countries often rely on technical expertise and other support from the international community during the development and implementation of their national instrument. This indicates the value of some form of consultative or joint process. The higher the consultative level, the higher the legitimacy of a national instrument, the national ownership thereof, and the international acceptance of it will be. Consultative processes therefore significantly lower the risk of the resulting instruments being merely symbolic.

Consultative processes are an opportunity for a government to demonstrate its primary role in addressing internal displacement and to bring all relevant actors, including donors, in a country together to have relevant discussions, to solve misunderstandings, and to find agreement on relevant notions and concepts and a way forward in addressing and ending a displacement situation. Such processes put IDPs at their heart and thus help to overcome their hopelessness, despair and frustration. 'This is the happiest day in my life in a long time', concluded a displaced man in his speech at the end of Kenya's stakeholder forum on the national IDP policy in 2010. The Internal Displacement Monitoring Centre, together with the University of Bern and the Brookings Institute, is currently developing a guide for practitioners on national law and policy making. The guide will steer law and policymakers through the different stages of developing a national instrument at the national level and will assist in framing its content.

\subsection{A flower bouquet: varieties in national law and policy making}

A growing number of countries across the world have enacted specific national instruments on internal displacement or are in the course of doing so. Existing national instruments vary greatly ${ }^{48}$ with respect to their

\footnotetext{
${ }^{48}$ See also, J Wyndham, 'A Developing Trend: Laws and Policies on Internal Displacement' (2006) Human Rights Brief 8-9; and Carr, above n 46, 36-40.
} 
development process ${ }^{49}$ but also with respect to their content, format, scope and their consistency with regional and international standards. Naturally, there is a broad variety in the content of existing national instruments, there is no general solution, and no universal model. ${ }^{50}$ This illustrates the fact that national instruments reflect the context of the country concerned, the particularities of each displacement situation and the political opportunities at the time of development.

A national instrument may be one integrated IDP-specific instrument that covers exclusively all matters related to internal displacement in one country cutting across all relevant sectors of regulation. It is also possible to opt for sectoral regulation of IDP-specific matters, typically relating to social welfare, education, health, birth registration, documentation, housing, land and property, compensation ${ }^{51}$ and other relevant national regulations. In some circumstances, a displacement-specific instrument also warrants additional sectoral regulation. This is the case where the instrument provides only the framework for IDP protection, or where a national law or policy requires amendments in some thematic sectors in order to bring existing regulations into line with the displacement-specific instrument, or to fill gaps identified by this instrument.

In light of the different country- and displacement-specific contexts, national instruments vary in their scope. The Ugandan National Policy for Internally Displaced Persons of $2004^{52}$ is probably the one document that approximates comprehensiveness. Kenya's draft policy on the prevention of internal displacement and the protection and assistance to IDPs in Kenya, although not yet adopted by Cabinet, is a comprehensive model policy. ${ }^{53}$ Liberia is also an interesting example in this respect,

\footnotetext{
${ }^{49}$ See sub-section 4.3 above.

${ }^{50}$ There is a model legislation annexed to the Great Lakes Protocol to facilitate the domestication of the instrument and the UN Guiding Principles on Internal Displacement. However, several countries opposed the idea of having this model legislation because they felt it intruded on their national sovereignty. In addition, there are certain risks entailed in the use of such model legislation, especially when national drafters are unfamiliar with the incorporation of international law in general and with the matter of internal displacement more specifically. Furthermore, model legislation does not take into account important differences in the legal traditions of different countries. The model legislation to the Great Lakes Protocol has, however, not often been drawn from in relevant national processes, mainly because of the need to develop a country and situation specific national instrument. Using the model does somewhat hamper this and would furthermore negatively impact on the national ownership of the instrument.

${ }^{51}$ Turkey, Law no 5233 on the Compensation of Damages that occurred due to Terror and the Fight against Terror, July 2004, is an example of a sectoral law. While IDPs could profit from the compensation law, this law was not specific to IDPs. The scope of the law was, rather, on the type of damage (art 7) and thus also entitled non-displaced persons to receive compensation if damage occurred.

${ }^{52}$ Republic of Uganda, Office of the Prime Minister, Department of Disaster Preparedness and Refugees, The National Policy for Internally Displaced Persons, Aug 2004.

${ }^{53}$ Republic of Kenya, Office of the President, Ministry of State for Special Programmes, National policy on the prevention of internal displacement and the protection and assistance to internally displaced persons in Kenya, final consolidated draft, 24 Mar 2010.
} 
as its Instrument of Adoption of $2004^{54}$ fully incorporates the Guiding Principles and thus at least suggests comprehensiveness.

Limitations to the scope are, however, possible, as long as there is adherence to the principle of non-discrimination. The scope of a national instrument may be limited to only one cause, to a particular geographic area in a country, to a particular phase of internal displacement or designed to only apply within a given timeframe. Limitations to only one cause or one phase of displacement are the most typical. The Colombian ${ }^{55}$ and Peruvian law $^{56}$ are limited to armed conflict and generalized violence as causes of conflict. But there are also instruments, such as India's National Policy on Resettlement and Rehabilitation for Project Affected Families, ${ }^{57}$ that relate to development-induced displacement. While a number of countries have adopted natural disaster management instruments, these are usually not devoted to the protection of persons displaced by such events, even if such instruments may be useful for the protection of IDPs in a given situation. Indeed, strong advocacy efforts are needed with governments of disaster-prone countries to include a protection angle in their national disaster management instruments. Instruments devoted to a particular phase of the displacement process often address only the phase of finding and sustaining durable solutions, such as the Angolan Norms on the Resettlement of the Internally Displaced Populations. ${ }^{58}$ At a minimum, a national instrument on internal displacement should address the core challenges a country is facing in addressing internal displacement. States that have assumed obligations under the Great Lakes Protocol, or that will have obligations under the Kampala Convention, are required to fully incorporate these instruments and thus may not limit the scope of their instrument.

With respect to the format of national instruments on internal displacement, we see legally binding instruments, such as the Angolan Decree on Norms on the Resettlement of Internally Displaced Persons of $2000,{ }^{59}$ the 1997 Colombian Law updated in 2000 and further developed in $2005,{ }^{60}$ or

\footnotetext{
${ }^{54}$ Liberia, National Transitional Government, The Guiding Principles on Internally Displaced Persons, Instrument of Adoption, 8 Nov 2004.

${ }^{55}$ Republic of Colombia, Law 387, 1997.

${ }^{56}$ Republic of Peru, Law 28223, on internal displacement, May 2004.

${ }^{57}$ India, Ministry of Rural Development, National Policy on Resettlement and Rehabilitation for Project Affected Families, 17 Feb 2004.

${ }^{58}$ Republic of Angola, Council of Ministers, Decree 79/02, Regulation for implementation of standards on resettlement of displaced populations, 6 Dec 2002.

${ }^{59}$ ibid.

${ }^{60}$ Above n 55, For the prevention of forced displacement; the care, protection, consolidation and socioeconomic stabilization of internally displaced persons displaced by violence in the Republic of Colombia, Decree 2569, Dec 2000; Decree 250, Feb 2005. The latter contains the adoption of a national plan to implement governmental policies on internal displacement and was triggered by the critical decision of the Colombian Constitutional Court, T-025, 2004.
} 
the Peruvian Law Concerning Internal Displacement of 2004; ${ }^{61}$ national policies, such as Uganda's National Policy for Internally Displaced Persons of 2004, ${ }^{62}$ the Sudanese Policy ${ }^{63}$ or the Iraqi National Policy on Displacement of $2008,{ }^{64}$ strategies, such as the Sri Lankan Joint Strategy Document for 2002-2003, ${ }^{65}$ or the National Strategy for Resolving the Problems of Refugees and Internally Displaced Persons of the Republic of Serbia 2002,66 or plans and programs, such as the Nepali Relief Program ${ }^{67}$ or the Azeri State Program for the Improvement of Living Standards and Generation of Employment for Refugees and IDPs. ${ }^{68}$

National legislation, on the one hand, and policies, strategies or plans, on the other, are not mutually exclusive. Laws or policies are often generic, stating general principles, entitlements of IDPs and obligations of the state, while strategies and plans tend to be much more specific, setting out activities, means, methods and allocation of roles and responsibilities to achieve a certain standard or aim. Laws and policies tend to regulate what is to be achieved, while strategies and plans state how the set out standards can be achieved. A policy, strategy or plan may complement and reinforce national legislation, for example, by identifying priorities, implementing the law or paving the way towards national legislation. ${ }^{69}$ A law or other form of legal regulation may strengthen a policy or strategy by amending and adapting, in order for the domestic legal framework to become compatible with the IDP policy or strategy. Where legal gaps or obstacles in the enjoyment of rights have been identified by a policy or strategy, adapting domestic legislation is also necessary to implement a policy or strategy. ${ }^{70}$ Kenya, for example, opted to develop a national policy, despite the country's obligation under the Great Lakes Protocol to domesticate the Guiding Principles technically requiring national legislation. ${ }^{71}$ However, in light of the neglected and unabated protracted displacement situation in Kenya and the prevailing political circumstances, the Kenyan Ministry of Justice

\footnotetext{
${ }^{61}$ Above n 56.

${ }^{62}$ Above n 52.

${ }^{63}$ Republic of the Sudan, Ministry of Humanitarian Affairs, National Policy on Internally Displaced Persons, 2009.

${ }^{64}$ Iraq, Ministry of Displacement and Migration, National Policy on Displacement, July 2008.

${ }^{65}$ Government of Sri Lanka/United Nations, Joint Strategy Document to Meet the Immediate Needs of Returned Internally Displaced Persons 2002-2003.

${ }^{66}$ Government of the Republic of Serbia, National Strategy for Resolving the Problems of Refugees and Internally Displaced Persons, 30 May 2002.

${ }^{67}$ Nepal, Relief Programme for Internally Displaced People due to Conflict for 2004-2005.

${ }^{68}$ Republic of Azerbaijan, Decree approving State Program for the Improvement of Living Standards and Generation of Employment for Refugees and IDPs, 1 July 2004.

${ }^{69}$ See, Mooney, above n 41, 3.

${ }^{70} \mathrm{On}$ the relationship between laws and non-legally binding instruments, see also, IDP Manual, above n 26, 27-29; and Framework on National Responsibility, above n 31, 16-17.

${ }^{71}$ The outcome document of the workshop on the implementation of the Great Lakes Protocol, Nairobi, July 2009, in Recommendation 4, provides to implement the Great Lakes Protocol 'by adopting legislation immediately ... or by first developing and implementing a policy or strategy'.
} 
and the Ministry of State for Special Programmes, together with national and international actors, have opted to first develop a national policy to have an overall framework to address the displacement situation and a basis for future legislation. In the meantime, Kenya has started drafting a bill on internal displacement based on and drawing from the policy.

The decision for one format or another is usually very much influenced by national legal and political traditions and the prevailing political opportunities at the time of development of the instrument. The key characteristic of laws and other forms of legal regulations is their legally binding nature, in which they state the rights and entitlements of IDPs and the respective obligations of national authorities, designate authorities and institutions in charge of implementation, and provide applicable judicial and administrative procedures for enforcement. Thus, laws are the strongest format for a national instrument on internal displacement. Law making is, however, a time consuming undertaking with prescribed procedures and many formalities, often requiring a legal review of domestic law before an IDP-specific law is drafted, or amendments in sectoral laws are made. Should a displacement situation warrant a more rapid solution, other formats, such as a policy, strategy or plan may be more appropriate to ensure the protection of IDPs. Such formats are usually developed with fewer formalities and are therefore swifter than laws. ${ }^{72}$

While policies, strategies or plans are not legally binding, they may, however, still be binding at the administrative level and constitute politically binding commitments for national authorities. Unlike laws, such formats provide the basis for organizing the response to internal displacement at the national level. ${ }^{73}$ The difference between these three formats is in practice often only gradual. A policy usually sets out applicable general principles and standards on the protection of IDPs specific to the particular country and displacement context. It furthermore contains an institutional part outlining the responsibilities of national authorities in line with their obligations and establishes a mechanism for coordination of the overall response to internal displacement. Strategic guidance to address particular challenges and gaps in the national response to internal displacement is provided by a strategy. Unlike a policy, a strategy identifies scenarios, options, methods and action points to address such challenges and gaps and allocates respective responsibilities. A plan is a very detailed and contextual scheme that identifies what needs to be done, when, how, by whom and with what financial means. Unlike policies or strategies, plans are not very well suited as stand-alone instruments but serve best in the implementation of a law, policy or strategy. This brief analysis and identification

${ }^{72}$ IDP Manual, above n 26, 28.

${ }^{73}$ ibid, 29. 
of some key characteristics of the different formats relates to their pure forms, but there are also instruments combining elements of a law or policy with elements of a strategy or a plan. The draft strategy of Yemen,${ }^{74}$ for example, while called a strategy, contains clear policy elements stating the obligations of the Government of Yemen and the rights of the displaced in the different stages of their displacement, and also identifies challenges to the rights of IDPs and provides possible means and methods to overcome these challenges. It was clear at the outset of the process in Yemen that the political leverage was very weak and would not support for a comprehensive policy document.

The idea of national instruments is not an imposition of the Guiding Principles, but instead means having an adapted and contextual instrument guided by the Principles and taking into account relevant prescriptions of international and regional law. The consistency of existing national instruments with norms of international and regional law, especially human rights law, also varies. Liberia's model,$^{75}$ by simply adopting the Guiding Principles, suggests full consistency, however, it lacks the contextualization and national ownership that is needed. It is worthwhile noting that an incomprehensive national instrument is not per se inconsistent with the Guiding Principles or in violation of international law. For example, an instrument limited in scope to the cause of armed conflict is not necessarily illegitimate. However, where the same country faces a disaster involving internal displacement, the disaster-induced IDPs must not be discriminated against because the instrument protects only conflict-induced IDPs. Problems arise where instruments contain outright violations of human rights, are discriminatory or otherwise fall beyond international and regional standards impeding IDPs in the enjoyment of their rights. In the African context, national instruments on internal displacement, if not carefully drafted and duly consulted, may become an obstacle to the ratification and implementation of the Kampala Convention. Respective states should therefore take the necessary care to ensure that their national instrument does not contradict the Kampala Convention or contain obstacles to the Convention's implementation. The same considerations apply with respect to the Great Lakes Protocol.

What format and scope to chosen depends first and foremost on the situation and the context in a given country. A variety of factors play a role, such as the actual displacement situation, the human and financial capacities of the state, the level of decentralization of government and powers, or the strength of other actors. Last but not least, the political denominator, in particular, the willingness and readiness of relevant authorities to

\footnotetext{
${ }^{74}$ Draft Yemen National Strategy on Internal Displacement due to Natural Disasters, Conflict and Other Causes, revised draft, 25 Oct 2010.

${ }^{75}$ Liberia, above n 54.
} 
address internal displacement in a planned, consistent and concerted manner, is an important factor that will determine what instrument is needed and what is possible.

\subsection{A national instrument - a matter of necessity?}

A situation where a national instrument on internal displacement may not be deemed necessary exists where national legislation is adequate to address the particular needs and vulnerabilities of the displaced population. Such an assessment requires however a thorough analysis of existing national legislation to ensure that it fully captures the specificities of the situation. National legislation will in many instances prove to be unsuitable or insufficient to address a displacement situation, because such general legislation is not designed for times of humanitarian crisis, nor takes into account the impact internal displacement has on the rights of affected persons. ${ }^{76}$

Where the displaced do not de facto have needs and vulnerabilities distinct from the general population, a specific instrument may not be appropriate. However, the mere fact of being displaced, having lost one's home, land and livelihood, having family and social ties disrupted, will in most situations render these persons particularly vulnerable and create distinct needs. ${ }^{77}$ Sometimes, it will be argued that IDPs' needs and vulnerabilities are similar to the people hosting them. Indeed, especially where IDPs seek refuge in poverty-stricken areas of their country, some of their needs and those of the host population can be similar, for example, the need to access health care and medication; other needs, however, such as the need for shelter, will remain distinct. Such similarities do not justify not developing a national instrument specifically addressing internal displacement. Rather, such an instrument should take into account the needs of the displaced and also other displacement-affected populations, such as host communities or communities that were left behind. ${ }^{78}$ Such an approach will be more appropriate, and will significantly lower the risk of tensions and hostilities against the arriving or returning IDPs. The draft documents of Kenya and Yemen ${ }^{79}$ have both taken this broader approach by explicitly including the

\footnotetext{
${ }^{76}$ This idea lies behind the development of the Guiding Principles on Internal Displacement. While international human rights and humanitarian law are applicable to a displacement situation, it is often not specific enough to address the particularities of a displacement situation adequately.

${ }^{77}$ E Mooney, 'The Concept of Internal Displacement and the Case for Internally Displaced Persons as a Category of Concern' (2005) 24 RSQ 14-21.

${ }^{78}$ The concept of displacement-affected populations was coined and first introduced by the former Representative of the UN Secretary-General on the Human Rights of Internally Displaced Persons, Walter Kälin, as an approach to better deal with IDPs outside camps. See, eg, 'Report of the Representative of the Secretary-General on the human rights of internally displaced persons, Addendum: Mission to Somalia', UN doc A/HRC/13/21/Add.2, 21 Jan 2010, para 48.

${ }^{79}$ Kenya, above n 53, Chapter III, paras 12-16; Draft Yemen National Strategy on Internal Displacement due to Natural Disasters, Conflict and Other Causes, revised draft, 25 Oct 2010, para III(2).
} 
displacement-affected communities. Especially in Yemen, where the great majority of IDPs have settled outside camps in urban and rural areas, not including the host communities and their needs would have been an assault to their hospitability.

In principle, the pre-existence of a displacement situation is not necessary in order to establish a national instrument. Certain circumstances may allow for the anticipation of displacement and encourage the development of a national instrument, such as a country's exposure to natural disasters, political instability, existing tensions, or an ongoing insurgency in a part of the country. Technically, it is not alien to but, rather, inherent in law and policy making to regulate issues in anticipation of them occurring. However, existing national instruments have all been put in place while facing internal displacement, which has allowed for the instruments to be tailored to the particular situation. Principles of prevention are therefore hardly ever included in national instruments and even obsolete in those that are limited in their application to a specific displacement situation. Colombia's law on internal displacement, with a well-developed policy on prevention of displacement, is an exception. Kenya's draft policy also includes prevention of future displacement as a core chapter, drawing from Colombia's law and mechanisms. ${ }^{80}$ In the course of drafting a bill on internal displacement in Kenya, a process that is currently ongoing, parliamentarians strongly supported the need to better highlight the prevention of internal displacement in the text so as to not institutionalize IDPs in Kenya. ${ }^{81}$ Reasons for not formulating instruments with future events in mind may, primarily, be hope and, sometimes, ignorance or sheer denial of the possibility of future displacement. Yemen's Deputy Prime Minister for Security and Defence requested the scope of the draft national strategy on internal displacement be limited to the displacement situation in the North, in denial of the instances of displacement, and the prospect of further displacement, in southern Yemen.

Other countries do not develop national instruments at all, even if necessary in light of the displacement they face. Pakistan's regime, for example, still officially upholds its position that the country is not facing a tremendous displacement crisis. This shows that developing and instituting a national instrument on internal displacement, however necessary such an instrument might be, clearly does not occur where there is no political will.

${ }^{80}$ Kenya, ibid, Chapter IV.

${ }^{81}$ The draft bill on IDPs in Kenya, as formally handed over to the Parliamentary Select Committee on 6 Dec 2012, thus contains strong sections on prevention. 


\subsection{Limits, risks, imperfection - why theory doesn't matter to IDPs}

Because internal displacement is politicized topic, as is the process of developing a national instrument, there are often problems entailed in such a process and its outcome.

Such a national instrument might only be used as a political statement and it might have been established without genuine intention and willingness to implement it to make a difference in the lives of the displaced. To counter the risk of such symbolic instruments and, more generally, to address the gap between texts and their implementation, a lesson can be learned, and three generic criteria be drawn, from Colombia's development of their legal framework on internal displacement. The instrument's binding or at least politically committing character should be formalized; institutional responsibility for its implementation should be anchored and resourced; and financial allocations for the effective implementation should be made. ${ }^{82}$

National texts short of compliance with regional and international standards risk undermining the normative achievements at the regional and international levels and limiting the protection these standards provide to IDPs. National instruments that use an IDP definition that significantly departs from the definition contained in the Guiding Principles may create discriminatory disparities between groups of de facto displaced persons. In the African context, in light of obligations under the Great Lakes Protocol and prospectively under the Kampala Convention, a departure from the internationally accepted IDP definition of the Guiding Principles is not legitimate. Of particular concern are national instruments conferring a particular legal status to IDPs, such as the Georgian or Azeri laws. ${ }^{83}$ Subsuming IDPs under one umbrella with refugees and migrants, or the application of refugee law principles to them, such as exclusion or cessation clauses, as in the case of Bosnia and Herzegovina's law, ${ }^{84}$ are also troubling. As citizens or habitual residents of the country within which they are displaced, IDPs do not need a particular legal status. Rather, their situation is a factual situation that often renders them vulnerable and creates special protection and assistance needs. A legal status is therefore not only unnecessary; it will often also be discriminatory. The Georgian law providing for a legal status of IDPs did not include all de facto IDPs and excluded some of them from receiving the support and benefits attached to the status. Also, the legal status itself is problematic, because such a status has to

\footnotetext{
${ }^{82}$ See, MJ Cepeda Espinosa, above n 44, 6-7 and 10-17.

${ }^{83}$ Law of Georgia on Internally Displaced Persons as amended in 2006; Law of the Republic of Azerbaijan 'On Status of Refugees and Forcibly Displaced Persons' of 1999.

${ }^{84}$ Law on Refugees from Bosnia and Herzegovina and Displaced Persons in Bosnia and Herzegovina as amended in 2003 .
} 
cease at some point. In the case of refugees, cessation of their status ${ }^{85}$ is a logical concept and, in most instances, simple to apply. However, cessation in the case of IDPs is more problematic and, unlike in the case of refugees, there are no clear-cut scenarios and criteria where an IDP ceases to be an IDP. Displacement ceases when a durable solution is found and sustained. Finding a durable solution is, however, a process with gradual diminishment of displacement-specific needs. ${ }^{86}$ These and other risks may be entailed in national law and policy making on internal displacement.

Certainly, national instruments have their limits. Unlike the direct provision of humanitarian assistance, the concept of protection per se, as the protection of the rights of IDPs ${ }^{87}$ is more difficult to handle and translate into tangible results. ${ }^{88}$ This holds particularly true for a national instrument on internal displacement that is no more than a piece of paper without effective implementation. Implementation of such instruments to make a difference to the protection of IDPs is the key, but also one of the big challenges encountered in many countries. The other major challenge, observed over the years, is inadequate national institutions and lack of capacity that threaten the development and implementation of such instruments ${ }^{89}$ This calls for joint and robust action by national authorities, civil society, international actors and, in particular, the donor community to align their operational and funding priorities with the national instruments that are in line with international and regional standards.

The particularities of each displacement situation and the countryspecific context require a tailored solution and not an imposition of the generic international law applicable to internal displacement. In light of the politicization of such processes and realities on the ground, expectations have to be realistic. Compromises are part of any negotiation and will often be reflected in national instruments, in particular if they were developed in an inclusive and consultative process. On the other hand, the mere possibility of negotiating on a national instrument addressing internal displacement will also create space for advocacy on protection concerns to influence the process and outcome. Compromises, while they may limit or weaken the document, often do not hamper the greater good such a national instrument brings for the protection of IDPs, and may sometimes

\footnotetext{
${ }^{85}$ Art 1(C) 1951 Geneva Convention relating to the Status of Refugees.

${ }^{86}$ Inter-Agency Standing Committee, 'Framework on Durable Solutions for Internally Displaced Persons', April 2010, 7.

${ }^{87}$ Protection relates to 'activities aimed at obtaining full respect for the rights of the individual in accordance with the letter and the spirit of the relevant bodies of law'; see, Inter-Agency Standing Committee, 'IDP Protection Policy', 1999; Global Protection Cluster Working Group, 'Handbook for the Protection of Internally Displaced Persons', Geneva, Mar 2010, 7.

${ }^{88}$ The Handbook, ibid, provides guidance on how the concept of protection can be operationalized.

${ }^{89}$ Carr, above n 46, 46, judges, 'Such laws and policies look good on paper, but they all fall at different hurdles'.
} 
be necessary to achieve a result. There are rotten compromises that should be abstained from, for example, compromises that would undermine the international and regional legal framework on the protection of IDPs. National instruments reflect a political process, a process that is necessary to create awareness of the displacement situation, to build national ownership of the document, to make national authorities acknowledge the displacement and assume their primary responsibility towards the displaced, and to alert them to address gaps in the response. Having a national instrument in place is an important achievement, but the preceding process is as important. Compromises and imperfection must realistically be expected. In theory, perfect results may be possible, but theory does not matter to IDPs.

\section{Conclusion}

The growing number of national instruments in countries across the globe indicates a clear trend towards the further development of the law on internal displacement through national law and policy making and even towards the establishment of customary rules. Unlike other realms of international law that have developed through the traditional top down approach, the law on internal displacement has been framed so far in a process of interaction between the international, regional and most notably the national level and the respective actors. In addition to this impetus, the demonstrated potential of national instruments to strengthen the protection of the rights of IDPs at the national level, to confirm the primary responsibility of national authorities in a national instrument, and to provide the basis for a coordinated response to internal displacement, avoiding unsystematic and $a d$ hoc action that would neglect many rights of the displaced, is a convincing argument for national authorities to develop national instruments and for the international community to support them in their endeavor.

Unlike direct humanitarian support, which mostly addresses the physical needs of the displaced, national instruments do not have direct impact on the fate of the displaced and are therefore not often a primary concern of national authorities faced with protection needs, nor a priority for international humanitarian actors or national civil society. Awareness raising among national authorities regarding the opportunities and potential of such national instruments is required and technical support should be given when necessary to develop such an instrument. Given the requirement under the Great Lakes Protocol and prospectively under the Kampala Convention, the development of national instruments on internal displacement will be a protection task in many African countries. Relevant international actors should be ready to support these countries to fulfil their obligations under these regional instruments. Promoting the 
ratification of the Kampala Convention is not enough; as a protection task, national law and policy making on internal displacement forms part of the responsibilities of the protection cluster. UNHCR, as lead agency of the global protection cluster, is best suited to regularly extend support and advice to national authorities in processes to develop national instruments, as it has done already in many contexts. UNHCR, as refugee agency, has vast experience in promoting and developing national legislation and has been very successful in the elaboration of national asylum instruments worldwide. To be able to do the same in the area of internal displacement, respective capacity and expertise must be strengthened and built in order for UNHCR to become a reliable support to national authorities. The Manual for Law and Policymakers ${ }^{90}$ is a useful tool to support such efforts. A forthcoming guide for national practitioners on national law and policy making on internal displacement will complement the Manual and guides national authorities through the process of developing their own national instrument to address internal displacement in their country.

Today, promotion of the Guiding Principles on Internal Displacement is not about their international standing, for that is accepted, but, rather, to ensure domestic implementation that is effective.

\footnotetext{
${ }^{90}$ See above n 26.
} 